\title{
Effective Educational Strategies Combining Emerging Genetic Science and Native American Cultural Issues
}

\author{
Lynne T. Bemis ${ }^{1}$ and Linda Burhansstipanov ${ }^{2}$ \\ ${ }^{1}$ University of Colorado Denver \\ ${ }^{2}$ Native American Cancer Research
}

\begin{abstract}
The purpose of this paper is to describe how new topics in genetic science are implemented and evaluated within Genetic Education for Native Americans (GENA ${ }^{\circledR}$ ) workshops. These workshops are typically implemented during professional conferences, training programs, Native American meetings and at tribal colleges. As genetic science evolves, public health educators are more and more likely to need to understand increasingly complex components within genetic research. These research discoveries are likely to impact cardiovascular health, cancer treatments, prevention and control of diabetes. The public and patients want to understand health information that affects them personally, as well as their communities. The focus of this paper is on GENA ${ }^{\circledR}$ objective 14 (emerging genetic science: microRNA), but the three 2006 3-hour workshops also addressed excerpts of GENA ${ }^{\circledR}$ objectives 5 and 29. at three meetings: the 2006 summer and fall Disparities Training Programs held in Houston, Texas and the 2006 Society for the Advancement of Chicanos and Native Americans in the Sciences (SACNAS) conference (October, Tampa, Florida). The emphasis on objective 14 is because it was updated during spring 2006 (initial focus was on stem cell research) and selected components of objectives 5 and 20 have been published elsewhere. The paper briefly describes the content, interactive learning opportunity and the evaluation from the three 2006 workshops. The overall findings verify the effectiveness ( $p$ value of less than .01) of GENA ${ }^{\circledR}$ to significantly increase knowledge level of workshop participants about emerging genetic science breakthroughs.
\end{abstract}

(C2007 Californian Journal of Health Promotion. All rights reserved.

Keywords: Native American, genetic education, microRNA, cultural issues

\section{Background}

The purpose of this paper is to describe how new genetic science is implemented and evaluated within Genetic Education for Native Americans (GENA $\left.{ }^{\circledR}\right)$ workshops. These workshops are typically implemented and evaluated during professional conferences, training programs, Native American meetings and at tribal colleges. The focus of this paper is on the edited 3-hour workshop that addressed three GENA ${ }^{\circledR}$ objectives at three meetings: the 2006 summer and fall Disparities in America - Working Towards Social Justice training held in Houston, Texas and the 2006 Society for the Advancement of Chicanos and Native Americans in the Sciences (SACNAS) conference (October, Tampa, Florida).
Genetic Education for Native Americans (GENA®) [R25 HG01866] was an education intervention study supported by the National Human Genome Research Institute (2007) from 1998 through 2003. The goals of GENA ${ }^{\circledR}$ were established based on Native American community needs expressed at focus groups and during individual meetings with community members in 1995-1997. Elders from Native communities expressed the need for information about genetic testing and research so that informed decisions about healthcare and participation in genetic studies could be made by Native leaders. Based upon elder Natives' guidance, the initial group for this education was Native college students. Thus, these young professionals could return to their communities and assist the elders and leaders in making decisions related to genetic research and related 
issues. The primary goal of GENA ${ }^{\circledR}$ was to provide culturally competent education about genetic research to Native American college and university students. The initial GENA ${ }^{\circledR}$ education study was very successful and ended in 2003. The GENA curriculum was implemented at over 20 professional meetings with over 500 participants from 1998 through 2003 and is described in other publications (Burhansstipanov, Bemis, and Dignan, 2001, 2002; Burhansstipanov, Bemis, Dignan, Dukepoo, 2001; Burhansstipanov, Bemis, Kaur, Bemis, 2005; Dignan, Burhansstipanov, Bemis, 2005; Romero, Bemis, Dignan, and Burhansstipanov, 2001). Participants included undergraduate and graduate students, community and faculty members. GENA ${ }^{\circledR}$ is team taught with a cultural representative as well as faculty from the fields of public health, molecular genetics, or classical genetics as part of each presentation. The team approach has been extremely successful as evaluated by preand post-tests as well as delayed assessment from $10 \%$ of participants. Assessments comparing the increased knowledge posteducation as compared to pre-education have revealed a gain of knowledge $(\mathrm{p} \leq 0.001)$ for all workshops where GENA ${ }^{\circledR}$ has been presented to date (Dignan et al., 2005). The overall level of interest in information pertaining to the human genome and genetics has been rated as extremely helpful and of need in the community. Members from other communities have expressed an interest in such programs for their own communities. Furthermore, GENA ${ }^{\circledR}$ workshops have been requested by scientists working with communities who realize that community values must be considered when initiating genetic or genomic research.

The NHGRI provided supplemental funding for new GENA ${ }^{\circledR}$ objectives to be developed, implemented and evaluated during 2003 through 2005. This supplemental funding resulted in Objective 26 What is a Cell?(specifically designed as a result of Native elders request and inclusion of hands on interactive experience); objective 26 on models for genetic basic science and cultural issues, objectives 27 and 28 on the HapMap Project, and objective 29 cultural issues, facts and myths.
Since 2003, an average of five GENA ${ }^{\circledR}$ workshops was held each year in geographically diverse regions of the US. An Audience Response System (ARS) that uses wireless electronic keypads increased the breadth and depth of GENA® participants' knowledge, attitudes, behaviors, opinions and workshop evaluation.

As of October 2005, GENA ${ }^{\circledR}$ was included within the (SACNAS) [R25 HG003200-02S1] grant. In addition to its regularly scheduled 3hour workshop held at the SACNAS Annual Conference, are two additional workshops each year at the Annual Disparities in America Working Towards Social Justice held in the summer and fall in Houston, Texas. Tailored three- to five-hour workshops are also implemented and evaluated at tribal colleges and community conferences.

During the spring of 2006, GENA® objective 14 was updated to address an emerging field of genetic research, microRNA. As is true with all GENA ${ }^{\circledR}$ objectives, each objective includes collection of data, instruction on the content specified in the objective, and an interactive participant learning activity to help reinforce learning. Because GENA ${ }^{\circledR}$ workshops integrate basic science and cultural issues, objective 14 was partnered with excerpts of GENA ${ }^{\circledR}$ objectives 5 (community based participatory research [CBPR]) and 29 (cultural issues). Three GENA ${ }^{\circledR}$ workshops were held from June through October that included this combination of objectives.

This paper is primarily focused on objective 14 because selected components of objectives 5 and 20 have been published elsewhere (Burhansstipanov et al., 2005; Romero et al., 2001). This paper briefly describes the content, interactive learning opportunity and the evaluation from the three 2006 workshops: two held at the Disparities Trainings (Houston, TX) and one at SACNAS (Tampa, FL).

\section{Description}

The target population for both disparities conferences is very mixed. The summer group includes a large proportion of faculty and 
researchers from multidisciplinary fields while the fall group is largely undergraduate students. The target population for the SACNAS conference is primarily Native and other minority students and faculty who teach underrepresented minorities in the sciences. The GENA ${ }^{\circledR}$ workshop held summer and fall 2006 included objective 14 and the summer session also included excerpts of two GENA ${ }^{\circledR}$ cultural objectives. The SACNAS conference addresses the same GENA ${ }^{\circledR}$ objectives as did the summer Disparities Conference. These workshops illustrated the methods used to address requests for information about current advances in genetic science. GENA ${ }^{\circledR}$ objective 5, "the participant will be able to identify the types of genetic research that are of interest / priority to Native communities," describes types of genetic research of interest/priority in native communities, summarizes information about historic interest of Native communities in genetic research and emphasizes current methods to employ when conducting research studies in partnership with Native communities. In addition, excerpts from objective 29, "the participant will be able to distinguish between facts and fallacies regarding common genetic issues" were included (i.e., "excerpts" because objective 29 includes embedded ARS opinion items and interactive discussions and requires 5 hours to complete the entire objective). Collectively, these two objectives focused on the use of community-based participatory research (CBPR) methodologies for genetic research in Indian Country, the limited use of specimens and the storage of genetic specimens as examples of issues of concern in Native communities. A description of GENA ${ }^{\circledR}$ objective 5 related to CBPR is described elsewhere (Romero et al., 2001). The interactive activity for Objective 5 is a small group discussion of one of five controversial case studies based on actual genetic research implemented in Indian Country. GENA ${ }^{\circledR}$ objective 29 includes ten issues frequently of concern to Native communities and is also described elsewhere (Burhansstipanov et al., 2005). Due to the limited time in the three workshops, the interactive activity for objective 5 was not included, but the participant interactive activity for objective 29 was included. The ARS was used to collect participants' opinions about Native American issues after and during discussion of the three issues included in the workshop (CBPR, storage of specimens, limited use of specimens). Examples of selected participants' responses are included in the findings section of this paper.

GENA ${ }^{\circledR}$ objective 14, "the participant will examine current genetic research-related issues and discoveries and their potential impact for Native communities" allows the faculty to update the content based on new or emerging breakthroughs in genetics, genomics and/or other science technologies. Thus, the initial 2001 content for objective 14 was on stem cell research. The focus of this objective in 2006 was microRNA and focus for this objective in 2007 will be on nanotechnology and its application to genetics. As the pace of new technology development increases so does our need for understandable information describing these technologies to people who are not in the same field or may have little basic science background. Previous students participating in GENA ${ }^{\circledR}$ during the annual SACNAS scientific meeting, requested more up-to-date science information be included in a community sensitive format (thus the combination of objective 14 with objectives 5 and 29). Based upon the students' requests, the authors updated objective 14 to describe the cutting edge topic of microRNAs.

\section{Rationale for Focusing on microRNA}

Objective 14 is designed to allow adaptations and updates to include new technology or science within GENA ${ }^{\circledR}$. The update used in three of the 2006 GENA ${ }^{\circledR}$ workshops is on the new topic of microRNAs, described below. MicroRNAs were selected as the updated topic for objective 14 for multiple reasons. MicroRNAs, although only recently discovered are found to regulate more than one third of the genes in plants, animals and humans (Ouellet, Perron, Gobeil, Plante, Provost, 2006).

MicroRNAs are misregulated in disease. MicroRNAs are relevant to Native communities and the general public as they offer new therapeutic targets in multiple diseases. 
Specifically, microRNAs have been implicated in diabetes by regulating the expression of insulin in response to glucose deprivation (Poy, Eliasson, Krutzfeldt, 2004), they have been implicated in a number of cancer types including, lung cancer, breast cancer and leukemia (Calin, Liu, Sevignani, Ferracin, Felli, Dumitru et al., 2004; Iorio, Ferracin, Liu, Veronese, Spizzo, Sabbioni et al., 2005; Takamizawa, Konishi, Yanagisawa, Tomida, Osada, Endoh et al., 2004). These diseases are largely responsible for the disparities in health in our communities and therefore public health and medical personnel will be called on to explain these new entities to patients and the general public.

Actually it is expected that most cellular processes are influenced by microRNAs because it is predicted that over one third of the human genome is regulated by these cellular entities. The GENA ${ }^{\circledR}$ faculty provide education on new concepts at the disparities conference to keep healthcare professionals up to date and to encourage young investigators into new areas of research. MicroRNAs explain many aspects of biology that were previously incomprehensible or ignored. They are expected to contribute to the next wave of therapeutics for a variety of previously untreatable conditions.

\section{Brief Review of Genetic Science}

Most public health educators understand basic genetics, chromosomes, DNA and RNA. However, health educators and health care providers rarely receive more than a general overview of genetics. As genetic science evolves, public health educators are more and more likely to need to understand more complex components within genetic research. Public health educators will likely need to explain this type of science to the public as medical treatment options become available based on microRNA research. For example, Native communities are sometimes uncomfortable in taking part in genetic research, testing, or treatments that are based on stored genetic specimens, and/or cell lines. However, much of the ongoing microRNA research can evolve using online databases and may not initially require new specimen collection. A public health educator may need to clarify common misinformation about microRNA medical treatments (once they become available) to community leaders before it is acceptable for tribal members to take part in studies using microRNA.

Unfortunately few public health education courses explain that although DNA can be copied into messenger RNA (mRNA) that codes for proteins in the body there are many more RNA molecules that do not code for proteins. The National Human Genome Research Institute (NHGRI) identified the location of genes included on the human chromosomes in 2001. The NHGRI Genome Project and others created genetic and physical maps of the human genome and located about 30,000 genes within the human genome. The genes were decoded at the base pair level. These bases are presented as four letters (i.e., the DNA bases are AGTC, but in RNA the bases are represented as AGUC; the "T" becomes a "U"). The Genome Project decoded the genome, letter by letter, clarifying the exact sequence of all 3 billion nucleotide bases that make up the human genome. To illustrate the complexity of this sequencing, if these nucleotide bases (ATGC) for the human body were written out in sequence (i.e., the nucleotide bases that comprise all 24 of the chromosomes, genes, DNA, RNA, mRNA), it would take 5,000 books to record all of the letters that make up one person's human genetic codes. Based upon information learned from the Human Genome Project, scientists understand that human beings are $99.9 \%$ similar to one another. Each human being has about 3 billion base pairs of DNA in their genetic material. The $0.1 \%$ difference from one human being to another comprises about 3 million base pairs (i.e., 3,000,000,000 X $0.001=3,000,000$ base pairs). For more than 40 years, genetic researchers studied DNA and RNA. During that time the microRNAs were thrown out with what was thought of as the waste material. However, once the Human Genome Sequence was available microRNAs were discovered by computational methods and comparisons to other organism genomes. 


\section{Basic Overview of microRNA}

MicroRNAs are a component of all mammalian cells. They are so small that they were lost or ignored in earlier studies of cellular components. In early studies it was thought that the most important process in mammalian cells was the transcription of DNA into messenger RNA which was then translated into protein. This process of DNA to RNA to Protein is called the Central Dogma of Biology. However, only 2\% or so of the human genome follows the central dogma and yet as much as $95 \%$ of the human genome is transcribed from DNA to RNA. There are many types of RNA molecules that were previously unidentified. Now through new computational methods of studying the human genome we know that one such group of RNAs is the microRNAs. These are small RNAs that can turn genes off. MicroRNAs are 21-25 nucleotides long. They function by binding to "messenger RNA" (mRNA) and blocking translation of the mRNA or causing degradation of the mRNA thereby blocking protein production. An example of the importance of microRNAs in human disease is the loss of microRNA 15 in leukemia. The loss of microRNA 15 in these cells prevents the leukemia cells from dying (Cimmino, Calin, Fabbri, Iorio, Ferracin, Shimizu et al., 2005).

MicroRNAs in the genome may overlap with other genes. They may be in the introns (part of the mRNA that is removed before expression). They may also be in the spaces between known genes these are called intergenic regions (Mendes Soares, Valcarcel, 2006). Where have microRNAs been all this time? For the 40 or more years we have been studying DNA and RNA the microRNAs were thrown out with the waste. Once the human genome and the genomes of other organisms were available microRNAs were discovered mostly by computational approaches. Computational methods can predict sequences in the genome that might act like a microRNA but they are merely predictions of biological behavior. Computational biology is used to predict sequences in the genome that can take on a specific shape called a stem loop structure. The microRNA is copied from the DNA and as it is transcribed it takes on the stem loop structure

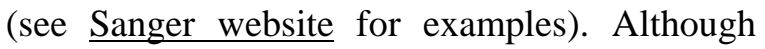
they are predicted to have the correct structure each microRNA must be confirmed to be functional in the laboratory by experimentation.

MicroRNAs were initially discovered in around 1993. They were initially described in the model organism Caenorhabditis elegans (C. elegans), a nematode or a small round worm (Lee, Feinbaum, Ambros, 1993; Wightman, Ha, Ruvkun, 1993). In worms, a gene was identified that regulated the expression of a protein and by the rules of the central dogma of biology the gene should have encoded a protein but it did not. The researchers eventually showed that the RNA transcribed from this gene was blocking the expression of the target protein. Thus, these were the first studies to show that the mature microRNA can find its target and block gene expression. In cancer a microRNA could be shutting down a gene that prevents cancer or if a microRNA is lost (e.g., through mutation), a gene that should not be present can not be turned off. MicroRNAs have multiple targets, since microRNAs can bind imperfectly more than one gene can be targeted in the same cell at the same time by the same microRNA (Shivdasani, 2006).

The petunia is an interesting example of the function of small RNAs because the gene for purple color can be suppressed by small RNAs leaving white patches (Ouellet et al., 2006). In plants, the small RNAs that are similar to microRNAs are called, "Small interfering RNAs” (SiRNAs). However, in mammalian cells SiRNAs are a reagent designed and used by researchers to shut down protein production of a specific gene. SiRNAs targeting specific genes in cancer have been tested in clinical trials and may be used in the future as therapies blocking the expression of genes normally regulated by microRNAs.

Scientists expect to see new therapeutics targeting microRNAs as well as new therapeutics designed to mimic microRNAs. It is likely that these targeted therapies will be expensive. Hopefully these will become available as therapeutics and be available to all people. Increasing student knowledge about heath disparities and combining that with 
knowledge of current technologies we hope that future generations will be able to better address the problem of health disparities. Not only by recognizing the need to provide exceptional health care to all but also with creative solutions based on sound science.

\section{Explanation of the microRNA Participant Interactive Activity}

All GENA ${ }^{\circledR}$ objectives include an interactive activity to help the participant understand the science or cultural issue focused on in each objective. For GENA ${ }^{\circledR}$ 14, strips of laminated pieces of colored paper, labeled as messenger RNA with a patch of Velcro ${ }^{\circledR}$ on the face/top (see Figure 1) or small squares of laminated microRNA that have small patches of Velcro ${ }^{\circledR}$ on the back (see Figure 2) are distributed to the workshop participants (see Figure 1). The black square in Figure 1 is the Velcro ${ }^{\circledR}$ patch. The colors of the laminated strips represent the three diseases most commonly associated with health disparities, heart disease, diabetes and cancer. The longer strip is a model of a messenger RNA that usually makes a protein in one of these diseases. Its production may be stopped if combined with the microRNA of the same color. For example, if the pink strip of the messenger RNA that creates a protein that helps prevent cancer is attached via Velcro ${ }^{\circledR}$ with the pink microRNA, the body has lost some of its protection against that type of cancer. However, if no microRNA (the small pink square in Figure 2) attaches to the pink messenger RNA for cancer, the body retains some protection against that type of cancer. This example illustrates the
microRNA acting as an oncogene and turning off a tumor suppressor. Equally likely is the circumstance where a microRNA is missing and a gene that causes cancer, an oncogene is not down regulated in an appropriate manner. However, for the activity in the workshop it is assumed that each messenger RNA is something that should be turned off for a better outcome in the disease. Workshop participants are asked to hold their respective pieces of laminate messenger RNA or micro RNA and to find someone who has the corresponding laminated sheets (i.e., pink messenger RNA can only attach to pink microRNA). Those individuals with messenger RNA, but were unable to find a corresponding microRNA are asked to stand in the front of the room. The others stand together in pairs (pink along the right wall, green along the back wall and blue along the left wall). Each "group" along the wall is asked what their attached laminated pieces of paper represent. Those with no attached messenger RNA for cancer (pink strips of lamination) respond that they retained some protein expression and have some protection from the cancer causing protein. Those with no attached messenger RNA for diabetes (green strips of lamination) respond that they too have retained some protection against diabetes. Likewise, those with no attached messenger RNA for heart disease (blue strips of lamination) have also retained some protection against heart disease. There are so many genes regulated by microRNAs equally likely is the opposite effect but for the simplicity of the activity we use the positive effect of microRNAs on the given disease.

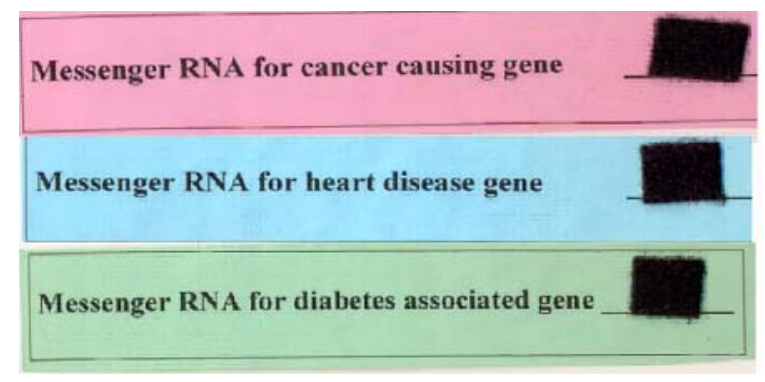

Figure 1

Participant Interactive Activity: Laminated strips of messenger RNA. A patch of Velcro® on the face/top. 

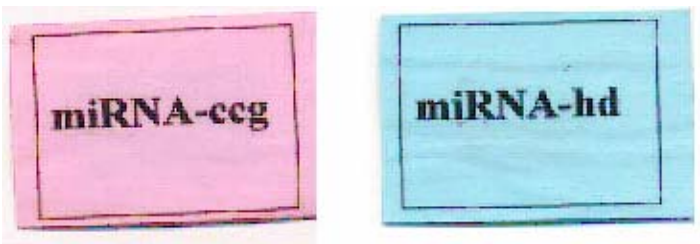

Figure 2

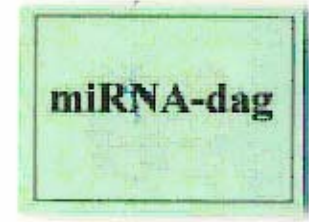

Participant Interactive Activity: Laminated strips of messenger RNA. Small squares of laminated microRNA have small patches of Velcro ${ }^{\circledR}$ on the back.
For the pairs of participants that have messenger RNA for cancer and microRNA attached (pink strips attached via Velcro ${ }^{\circledR}$ to the small squares of microRNA), they explain to the group that their protective protein was not produced because of the micro RNA and they have lost some protection against this type of cancer. Comparable explanations are provided for those with diabetes messenger RNA attached to microRNA and heart disease messenger RNA attached to microRNA (blue). The workshop participants return to their seats and the faculty provide real life explanations of break-through science for these activities, such as melanoma for the cancer example.

Another example of how the vast amount of information in databases about microRNAs has been used to provide learning opportunities for students is a project implemented by one of the GENA faculty members. Students in Dr. Bemis' Molecular Genetics class used data base searches to identify genes that might be regulated in cancer. They chose known genes and then identified putative microRNAs that might regulate them. They were then able to show that the microRNAs they predicted to be important were upregulated in the cancer cells they predicted. They were correct at least 50\% of the time. The vast amount of data available can be used for training opportunities at every level of education

\section{Demographics of the SACNAS and Houston Disparities GENA ${ }^{\circledR}$ Workshop Participants}

The ARS was used to collect the participants' (1) demographics and self-report behaviors/ experiences; (2) pre-workshop knowledge; (3) opinions on selected genetic and cultural issues; (4) post-workshop genetic knowledge; and (5) overall GENA ${ }^{\circledR}$ workshop evaluation. Forty three participants attended the June 25, 2006 Houston Disparities Workshop; thirty eight attended the September 2006 Houston Disparities workshop and SACNAS averaged 35 participants. The total average number of responses to most items was 116 . Age range was from the 30's to 60's. The largest proportion were African-American (42.5\%), followed by Non-Hispanic Caucasian (28.2\%), Native American (i.e., American Indian, Alaska Native, Pacific Islander) (26.9\%), Hispanic (23.1\%), and Asian (9\%). Sixty-five percent had at least a college baccalaureate degree: College BA or BS $(n=28 / 118,23.7 \%)$; masters degree $(n=24 / 118$, 20.3\%); doctorate $\quad(\mathrm{n}=23 / 118, \quad 19.5 \%)$; obviously, a highly educated group. Almost one quarter $(23.5 \%)$ of the participants were researchers and almost one-fifth (18.6\%) in the field of public health policy.

To help the GENA ${ }^{\circledR}$ faculty understand how to modify explanations in real time while implementing the workshop, we ask a few questions about genetics education background. In this group prior to the GENA ${ }^{\circledR}$ workshop, a large proportion had more than ten hours of genetic education (41.8\%) and one-fifth (21.5\%) had never had any genetic educations.

\section{Pre and Post-Workshop Knowledge Scores}

The focus of this paper is on the 2006 GENA ${ }^{\circledR}$ workshops that included objective 14, on microRNA (although cultural issues were also included in these sessions). The same five microRNA knowledge items were included for 
both the pre- and post-workshop knowledge items (see Figures 4). The average percent correct was $26.4 \% \%$ on the pretest. This low of people, even researchers are unfamiliar with the topic. In addition behavioral scientists and policy professionals comprised the workshop participants in two of the three GENA ${ }^{\circledR}$ objective 14 sessions. These individuals have little to no bench science experience. The average correct percentage for the five microRNA multiple choice items was $84.9 \%$, an increase of $58.5 \%\left(\mathrm{p}^{>} .001\right)$.

\section{The Workshop Evaluation for the GENA ${ }^{\circledR}$ Session}

Three items are asked to rate the overall evaluation of the GENA ${ }^{\circledR}$ session. The first is on how understandable was the workshop. More than two thirds $(75.9 \%)$ of the participants responded "very understandable". The second questions is "Overall this session provided useful information to me", and all of the participants either responded "I strongly agree" (62.1\%) or "I agree (37.9\%). When asked to evaluate the quality of the content, the majority (89.7\%) ranked the content as "high".

In addition, the GENA ${ }^{\circledR}$ faculty keeps track of participants' opinion about use of the ARS keypads and their impact on learning. The majority of participants (89.7\%) responded that the ARS keypad system improved their learning and $11.1 \%$ weren't certain whether the ARS affected their learning. Likewise, the majority (89.7\%) wanted to have the ARS keypad system used at future sessions.

\section{Conclusions / Discussion}

Genetic and genomic science is evolving and public health educators will need to explain how new treatments. Objective 14 is an example of new and complex scientific findings that are likely to influence selected chronic disease care in the future. Although GENA ${ }^{\circledR}$ objective 14 was complex, the majority of participants at all three of the 2006 workshops clearly understood the basic science by the end of the session. The public health educators who had never had any genetic science prior to this workshop had lower scores than did the basic scientists, the students with more lab experience, and the basic science faculty. This emerging area of science requires that public health educators increase their basic understanding of genetics to better enable them to accurately describe new therapies and assist patients in understanding new state-of-the-art care so that they can make informed choices about whether or not they wish to receive the new therapies. These therapies are not yet available, but preliminary findings from multiple studies indicate that clinical trials for selected conditions may be available within the next decade.

The ARS continues to provide improved data collection and evaluation. As is clear from the participants' responses, most (89.7\%) want to have the keypads at future workshops. The ARS reduces the risks of data coding errors and converts into Excel ${ }^{\circledR}$, then SPSS ${ }^{\circledR}$, SAS ${ }^{\circledR}$ or SUDAAN ${ }^{\circledR}$ within a few minutes of completing the workshop. Likewise, for demographic and opinion items, the workshop participants are able to view the responses on the screen immediately. The pre-workshop knowledge items are not displayed on the screen, but the post-workshop knowledge items are. The participants enjoyed seeing how well they did on the objective 14 post-test. The workshop evaluation items (e.g., how understandable, useful was the content) also do not display the findings to avoid participant bias on subsequent items.

\section{References}

Burhansstipanov, L., Bemis, L.T., Dignan, M. (2001). Native American cancer education: Genetic and cultural issues. Journal of Cancer Education, 16(3), 142-145.

Burhansstipanov, L., Bemis, L. T., Dignan, M. B. (2002). Native American recommendations for genetic research to be culturally respectful. Jurimetrics, 42, 149-57.

Burhansstipanov, L., Bemis, L. T., Dignan M. B., Dukepoo, F. (2001). Genetics education: Development of genetic education curriculum for Native American college and university students. Genetics, 158, 941-948. 
Burhansstipanov, L., Bemis, L., Kaur, J. S., Bemis, G. (2005). Sample genetic policy language for research conducted with Native Communities. Journal of Cancer Education, 20(Suppl.), 52-57.

Calin, G. A., Liu C. G., Sevignani, C., Ferracin, M., Felli, N., Dumitru, C. D. et al. (2004). MicroRNA profiling reveals distinct signatures in B cell chronic lymphocytic leukemias. Proceedings of the National Academy of Sciences, 101, 11755-11760.

Cimmino, A., Calin, G. A., Fabbri, M., Iorio, M. V., Ferracin, M., Shimizu, M. et al. (2005). miR-15 and miR-16 induce apoptosis by targeting BCL2. Proc Natl Acad Sci U S A., 102(39):13944-9.

Dignan, M. B., Burhansstipanov, L., Bemis, L. (2005). Genetic education for Native Americans evaluation methodology and results. Genetics, 169, 517-521.

Iorio, M. V., Ferracin, M., Liu, C. G., Veronese, A., Spizzo, R., Sabbioni, S. et al. (2005). MicroRNA gene expression deregulation in human breast cancer. Cancer Research, 65, 7065-7070.

Lee, R. C., Feinbaum, R. L., Ambros, V. (1993). The C. elegans heterochronic gene lin-4 encodes small RNAs with antisense complementarity to lin-14. Cell, 75, 843-854.

Mendes Soares, L. M., Valcarcel, J. (2006). The expanding transcriptome: The genome as the 'Book of Sand'. The EMBO Journal, 25, 923-931.

National Human Genome Research Institute. (2007). Bringing the genome revolution to the public. Retrieved November 10, 2006, from http://www.genome.gov/

Ouellet, D. L., Perron, M. P., Gobeil, L. A., Plante, P., Provost, P. (2006). MicroRNAs in gene regulation: When the smallest governs it All. Journal of Biomedical Biotechnology, 2006, 69616.

Poy, M. N., Eliasson, L., Krutzfeldt, J. (2004). A pancreatic islet-specific microRNA regulates insulin secretion. Nature, 432, 226-230.

Romero, F., Bemis, L. T., Dignan, M. and Burhansstipanov, L. (2001). Genetic research and Native American cultural issues. Journal of Women and Minorities in Science and Engineering, 7, 97106.

Shivdasani, R. A. (2006). MicroRNAs: Regulators of gene expression and cell differentiation. Blood, 108, 3646-3653.

Takamizawa, J., Konishi, H., Yanagisawa, K., Tomida, S., Osada, H., Endoh, H. et al. (2004). Reduced expression of the let-7 microRNAs in human lung cancers in association with shortened postoperative survival. Cancer Research, 64, 3753-3756.

Wightman, B., Ha, I., Ruvkun, G. (1993). Posttranscriptional regulation of the heterochronic gene Lin-14 by Lin-4 mediates temporal pattern-formation in C. elegans. Cell, 75, 855-862.

\section{Acknowledgements}

Genetic Education for Native Americans (GENA ${ }^{\circledR}$ ) was developed through the National Human Genome Research Institute (NHGRI), Ethical, Legal and Social Implications (ELSI) Section [grant \# HG01866;

PI: L. Burhansstipanov], and through the Society for the Advancement of Chicanos and Native Americans in Sciences (SACNAS) subcontract with the NHGRI [Grant \# R25 HG003200-02S1 PI: M. L. Linton]. In addition, partial support for GENA ${ }^{\circledR}$ is from Mayo Clinic’s Spirit of Eagles Community Network Programs [U01 CA 114609; PI: J.S. Kaur]. Special thanks to Joy Boyer, David Burgess, and Clifton Poodry for their continued support and assistance in helping the authors make new genetic information understandable in a culturally respectful manner for Native Americans and others.

URL for further information: information about upcoming GENA ${ }^{\circledR}$ conferences will be included on the NACR website (http://www.NatAmCancer.org) beginning winter 2007. 
$\underline{\text { Author Information }}$

Lynne T. Bemis, Ph.D.

Associate Professor of Medicine, Medical Oncology

University of Colorado Denver

L18-8403H

12801 E. 17th Ave

Aurora, CO 80045

Ph.: 720-560-0278

Fax.: 303-724-3889

E-Mail: Lynne.Bemis@uchsc.edu

Linda Burhansstipanov, MSPH, DrPH, CHES

Executive Director

Native American Cancer Research

3022 South Nova Road

Pine, CO 80470-7830

Ph.: 303-838-9359

Fax.: 303-838-7629

Native Cancer Survivors' Support Network: 1-800-537-8295

E-Mail: LindaB@NatAmCancer.net

URL: http://www.NatAmCancer.org 


\section{Appendix A \\ Workshop Objectives and CHES Questions}

\section{CHES Objectives}

1. The participant will identify at least one example of the emerging science of microRNA.

2. The participant will identify the data collection used during GENA® microRNA.

\section{CHES Questions}

1. Which of the following is a potential use of microRNA in healthcare?

A. To catalog genes

B. To prepare improved medications derived from plant organisms

C. To increase microRNA expression so that protein production may be blocked.

D. To enhance glucose metabolism

Answer: D

2. Where are microRNAs often found?
A. In “junk” DNA
B. In the centromere
C. In the mitochondria
D. In plants

\section{Answer: A}

3. The Audience Response System (ARS) is used in GENA ${ }^{\circledR}$ to collect which of the following?
A. The participants mailing address
B. The participants' workshop registration information
C. Short answers to open-ended questions
D. The participants' demographics

\section{Answer: D}

4. Which of the following was ARS documented average increase from pre-workshop knowledge scores to post-workshop knowledge scores for GENA ${ }^{\circledR}$ objective 14 ?
A. $\sim 4.5 \%$
B. $\sim 36.5 \%$
C. $\sim 58.5 \%$
D. 75.5\%

\section{Answer: C}

